\title{
Community Disaster Resilience in the COVID-19 Outbreak: Insights from Shanghai's Experience in China
}

This article was published in the following Dove Press journal: Risk Management and Healthcare Policy

\author{
Liwei Zhang' \\ Ji Zhao ${ }^{2}$ \\ Jixin $\mathrm{Liu}^{3}$ \\ Kelin Chen ${ }^{4}$ \\ 'School of Public Administration, Jilin \\ University, Changchun, People's Republic \\ of China; ${ }^{2}$ School of International and \\ Public Affairs, Shanghai Jiao Tong \\ University, Shanghai, People's Republic of \\ China; ${ }^{3}$ School of Marxism, Tsinghua \\ University, Beijing, People's Republic of \\ China; ${ }^{4}$ Institute of Urban Governance, \\ Shenzhen University, Shenzhen, People's \\ Republic of China
}

Correspondence: Kelin Chen Institute of Urban Governance, Shenzhen University, Huiyuan Building, 3688 Nanhai Boulevard, Nanshan District, Shenzhen 518060, People's Republic of China Tel +86 I3581929963

Email chenkelin@szu.edu.cn
Purpose: Communities are central to the practice of public health emergency preparedness and response. This article mainly focuses on COVID-19 and discusses the formation and structure of community disaster resilience, which is an effective method for coping with such a public health emergency.

Methods: Based on the management of the COVID-19 outbreak in China, this article uses Shanghai's experience to illustrate how a community disaster resilience was formed for risk management. Resorting to the analytical framework of risk city, principles of community disaster resilience are given.

Results: Four actions can be recommended based on Shanghai's experience: 1) Applying a vulnerability analysis matrix for targeted risk governance, 2) empowering volunteer groups for emergency response, 3 ) policy and action for public health emergency prevention, and 4) risk communication for uncertainty-oriented planning.

Conclusion: Shanghai's experience offers a reference to tackle the COVID-19 at the global level. The COVID-19 outbreak highlights that humans still face various unpredictable health risks in the future. Forming a connection-based resilience at the community level is an effective way to risk management.

Keywords: community resilience, risk management, collaborative network, COVID-19

\section{Introduction}

Consensus has been reached that human beings are living in a "risk society". In other words, today's society is preoccupied with the notion of risk. ${ }^{1,2}$ Various risks, such as those associated with natural disasters, climate change, environmental pollution, terrorism, and large-scale pandemics, impact all aspects of people, organizations, and society at all levels. Briefly, sustainable development in modern society is, to a certain extent, dependent upon risk management strategies, whether existent or potential strategies. 3,4

Effective risk governance must focus on human space - particularly in terms of cities and urban communities. Furthermore, cities need to become key actors in the process of risk governance. ${ }^{5}$ Urban communities, as fundamental units of human habitat, play a vital role in responding to risks, as they are capable of gathering resources and collaborating actions in a swift manner. ${ }^{6,7}$ In order to highlight the capacity of communities, academics use the term "resilience" to suggest an effective model for risk governance. In the context of risk, the novel concept "community disaster resilience", which combines the concepts of community and resilience, 
is widely used in academic circles for describing how a community deals with the COVID-19 outbreak. ${ }^{8,9}$ Although the world has experienced serious pandemics such as SARS and MERS, in view of the severe situation caused by the COVID-19 which different countries face to, improving disaster resilience is still a vital issue for all countries to cope with public health emergencies and to save life and property.

In this article, we aimed to discuss the practice of community disaster resilience so as to illustrate its structure and process. We utilized the case of China's COVID19 outbreak management, and present the community experience in Shanghai to elaborate on how community disaster resilience may be shaped. During the COVID-19 outbreak, China adopted harsh countermeasures to tackle the spread of the virus. For instance, a typical policy in the response to COVID-19 was the strict (albeit of varying levels) grassroots mobilization of residential lockdownsfrom checkpoints at community entrances to rigorous limits on going outdoors. ${ }^{10}$ However, different communities in China utilized various restriction patterns for quarantine purposes in different provinces and cities. Compared to rigid strategies and failed experiences in some provinces, Shanghai's community adopted a distinctive measure that represents a type of community disaster resilience, which made sense in the context of responding to the COVID-19 outbreak. Shanghai's experience shows that a resilient community formed by diverse stakeholders' participation can achieve effective risk governance that reports no infectious cases and balances the normal life and social distance in the COVID-19 outbreak, even though the community faces to the complex demographic situation. By contrast, communities in other areas in China reveal totally different results. For instance, these communities only utilized enforcement measures and even violence, and cluster of infection also emerged. ${ }^{11,12}$ Therefore, it appears necessary to recommend Shanghai's method and to outline lessons for developing and implementing effective risk management for a public health emergency.

The remainder of this article is arranged as follows: Section 2 conceptualizes community disaster resilience based on the existing literature; Section 3 explains the background and experience of Shanghai and outlines the analytical framework of community disaster resilience; Section 4 illustrates lessons of community disaster resilience reflected from Shanghai's experience following the analytical framework; Section 5 concludes this article and indicates future avenues of research.

\section{Conceptualizing Community Disaster Resilience in the Public Health Emergency}

Community disaster resilience is rooted in the concepts of "resilience" and "community resilience". The concept of resilience has evolved from a term used within the disciplines of material sciences and environmental studies. Generally, although resilience has been used in a variety of contexts, it represents the capacity of adaptability and flexibility, which describes how a system positively adapts to a sudden pressure or adversity and how a system tackles abnormal or unexpected threats without changing beyond recognition. ${ }^{13,14}$ The concept of resilience in the urban context refers to the capacities of a system to undergo disturbance while maintaining its functions and controls. ${ }^{5,15}$ People, groups, organizations, and society can all be resilient. ${ }^{16,17}$

With respect to community resilience, there are many definitions with different perspectives. In brief, two key factors can be summarized from the existing literature related to community resilience research. First, community resilience is the ability of a community or its constituent parts to bounce back from the harmful impact of disasters. It is a type of adaptive, changeable, and recoverable capacity, by which a community is able to adapt and respond to emergencies in a disaster or risk context while continuing to sustain critical systems and to maintain the community's unique character. ${ }^{18,19}$ Second, community resilience is a holistic structure that integrates individuals, families, and organizations into a community. As a whole, the term community resilience describes a network of systems that directly influence human society at a grassroots community level. The vital premise of community resilience is a collaborative network in which people and organizations are connected to each other and work together. ${ }^{20,21}$

Community disaster resilience is akin to community resilience. For highlighting the context of emergency management, the concept of community disaster resilience is used to more accurately describe a community's capacity to adapt to change, to handle disruption, and to respond in a positive and timely manner to risk or emergencies. ${ }^{22-25}$ Any conceptualization of community disaster resilience needs to acknowledge the importance of various contexts; in other words, the contextualization of resilience is highly associated with the stressor, which can take many forms, ranging from natural to human-driven events. For instance, in a natural disaster, disaster resilience is dependent upon 
the built environment or physical infrastructure. In a terrorism risk, disaster resilience refers to counterterrorism techniques like intelligence system. ${ }^{26,27}$ Based on the objective of this article, we mainly focus on the community disaster resilience in the public health emergency.

As for public health emergencies, the H1N1 outbreak proved how vulnerable communities are to public health disasters, and how important it is that communities take action to prevent and restrict further pandemics. ${ }^{28,29}$ In detail, following RAND Corporation's definition, community disaster resilience related to public health entails three aspects: (1) Preventing, withstanding, and mitigating the stress of a health incident; (2) recovering from the incident and restoring at least the same level of health and social functioning afterward; (3) using knowledge from a past response to strengthen the community's ability to prevent the next health incident. ${ }^{30}$ By the previous knowledge and experience in the current experience, the authority or government can conduct targeted strategies for the present risk and design policy for tackling potential public health emergency in the future. ${ }^{31,32}$

Regarding community disaster resilience in the public health emergency, it is an effective and sustainable method for risk governance, which means that we can improve health conditions and quality of life, both in the present and in the future, in a way that maintains the environmental, social, and economic processes on which life depends. ${ }^{33,34}$ In essence, resilience serves as the ability of a system to sustain itself through change via adaptation and occasional transformation. Community resilience successfully responds to such change, thus making resilience critically important to the community and sustainability as a whole. ${ }^{35-38}$ In other words, community disaster resilience pertains to assisting the community to recover from disasters and to retain socio-economic vitality and community members' quality of life. To sum up, Figure 1 outlines a conceptual model of community disaster resilience based on our review.

\section{Methodology and Analytical Framework \\ Case Study}

As mentioned above, in response to the COVID-19 outbreak, the cities of China successively issued city-wide quarantine policies and travel restrictions. As communities were the fundamental units of the quarantine policy, such community lockdowns aimed to control clusters in public space and to maintain social distance. Indeed, in reality, community lockdowns make sense for reducing virus transmission and for overcoming outbreaks. However, such lockdowns from the city to the community level also involve ethical issues associated with limiting liberties. ${ }^{39}$ Clearly, different communities react to adversity in different and often numerous ways. This process is not merely the additive result of individual responses in the wake of a problem but results from the unique capacities that a community embodies prior to experiencing a hazard. ${ }^{40}$ From a macro-perspective, China's practice of outbreak management shows diverse effects at the community level. ${ }^{41}$ Compared to rigid strategies in some provinces of China, some communities in Shanghai adopted a distinctive measure that represents a form of community disaster resilience.

This article focuses predominantly on the experience and practice of the community of Lujiazui in Shanghai and explains how this community reflects a type of community disaster resilience. The representativeness of the Lujiazui community can be summarized as follows. Lujiazui is the

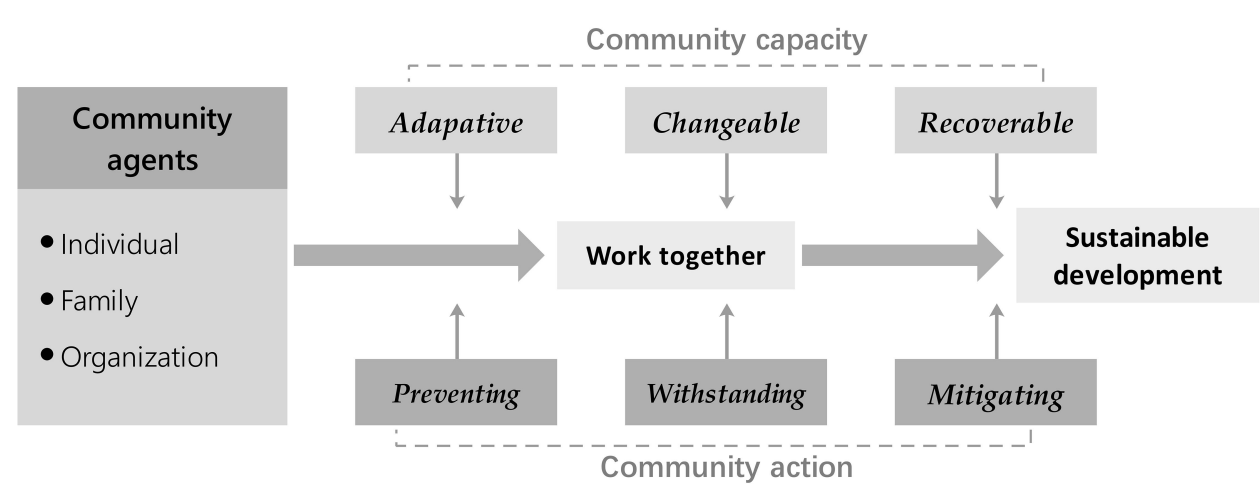

Figure I A conceptual model of community disaster resilience. 
financial center of Shanghai, and the Lujiazui community is one of the most prosperous regions in Shanghai with a large population. According to statistics, the population in the Lujiazui community is approximately 0.14 million, which includes approximately 50 thousand international residents. The Lujiazui community is one of the communities which have the most population in Shanghai. Besides, the density of the population of the Lujiazui community ranks at the top level comparing with other communities in Shanghai. ${ }^{42}$ In this sense, the Lujiazui community not only faced to the high density of the population but also needed to cope with the differences amongst diverse races in the outbreak management. Besides, compared to other community practices for responding to the COVID-19 outbreak in China, the community of Lujiazui altered the authoritative pattern and presented a governance form that used public participation while respecting personal liberty and individuality. Under such effort, the Lujiazui community reports no infectious case. Some of the materials used by the community of Lujiazui were collected from open-access sources, including governmental documents, official media, and social organizations' reports. Other materials came from the authors' participatory observations and in-depth interviews with the governmental officials, volunteers, and inhabitants of the community of Lujiazui. All materials are permitted to be used in this article.

\section{Analytical Framework}

In order to ensure the clarity of our analysis, this article utilized the conceptual framework of resilient cities as the analytical framework. As Jabareen indicated, the conceptual analysis method is a grounded theory technique that aims to generate, identify, and trace a phenomenon's major concepts that, together, constitute its theoretical framework. ${ }^{5}$ The reason we choose this framework is two-fold: (1) A conceptual framework can help us identify the core features and appearances of community disaster resilience, and (2) such a conceptual framework covers the core characteristics of a disasterresilient community, such as information sharing, public participation, and collaborative action. ${ }^{40}$ Table 1 lists four key concepts as the interrelated components of the conceptual framework.

According to the analytical framework, this article elaborates on the practice utilized by the community of
Lujiazui to respond to the COVID-19 outbreak and illustrates how the community expressed their method of disaster resilience.

\section{Results: Community Disaster Resilience of the Community of Lujiazui \\ Applying a Vulnerability Analysis Matrix for Targeted Risk Governance}

Asserting the vulnerability of an entity in the present situation presupposes a notion of possible future harm to said entity. Vulnerability is a present property that describes possible future harm, ie, vulnerability is a predictive concept. Briefly, identifying vulnerability is a vital step for completing scientific risk assessments and evidence-based risk management. ${ }^{43}$

In the public health field, particularly in the context of pandemic influenza, vulnerability refers to the group that is either the potential infectious source or is at risk of being infected. ${ }^{44}$ According to the framework of the vulnerability analysis matrix, demography and spatial distribution are two critical factors for assessing vulnerability. Demography involves different variables that affect the vulnerability of individuals and communities, such as income, education, gender, age, and physical and mental capacity. Spatial distribution demonstrates the spatial location of risks, uncertainties, vulnerabilities, and vulnerable individuals in communities. ${ }^{5}$

In the community of Lujiazui, an outbreak management map, developed according to the population distribution map, was utilized to identify risks at different levels. With the tide of "returning to work", the high population mobility intensifies the potential risk of human-to-human transmission. In order to avoid the spread of COVID-19, the community of Lujiazui issued colored entrance identification to residents. The different colors represent different people: Red indicates a healthy person, while white refers to a person in quarantine. When the person reaches 14 days in quarantine, he or she can switch their white identification to red in order to pass freely. Furthermore, the community authority marked residents from Hubei, where COVID19 originated, using red on the map, and people from non-Hubei areas and vacant rooms were marked using green and blue, respectively. Such a map illustrates the 
Table I Four Key Concepts of the Conceptual Framework of Resilient Cities

\begin{tabular}{|l|l|}
\hline Concept & Description \\
\hline $\begin{array}{l}\text { Vulnerability } \\
\text { analysis matrix }\end{array}$ & $\begin{array}{l}\text { The role of the vulnerability analysis matrix is } \\
\text { to analyze and identify the types, demography, } \\
\text { intensity, scope, and spatial distribution of } \\
\text { specific risks so as to enable mapping of the } \\
\text { future tendency of such risks and } \\
\text { vulnerabilities. }\end{array}$ \\
\hline Urban governance & $\begin{array}{l}\text { Urban governance represents a collaborative } \\
\text { network, including public agencies, private } \\
\text { sectors, various social groups, communities, } \\
\text { civil societies, and grassroots organizations for } \\
\text { responding to risks. }\end{array}$ \\
\hline Prevention & $\begin{array}{l}\text { Prevention indicates the necessity of } \\
\text { establishing and assessing policies to reduce } \\
\text { the occurrence of hazards. }\end{array}$ \\
\hline $\begin{array}{l}\text { Uncertainty- } \\
\text { oriented planning }\end{array}$ & $\begin{array}{l}\text { Uncertainty-oriented planning suggests that } \\
\text { planning ought to be made based on the } \\
\text { tendency of uncertainty, instead of } \\
\text { conventional approaches-either by } \\
\text { immediate action to secure the future, or by } \\
\text { preparing actions to be taken in case a negative } \\
\text { event occurs. }\end{array}$ \\
\hline
\end{tabular}

Note: The content of this table is summarized from Yosef Jabareen's <The Risk City $>$. $^{5}$

risk level in the community of Lujiazui, which enables the authorities to realize risk hotspots in the community. In addition, the authorities can also use this adaptive method to cope with at-risk groups.

According to epidemiological investigations, elderly persons are particularly vulnerable to infection; ${ }^{45}$ therefore, it is important to prevent an outbreak of COVID-19 in retirement homes. Thus, the Shanghai Municipal Authority required the community to focus on these institutes. Compared to the devastating outbreak of COVID-19 in the retirement homes of Madrid, Spain, actions designed to protect retirement homes in Shanghai have had an apparent positive result. In the community of Lujiazui, effective protection for retirement homes has resulted in these institutes becoming exempt from monitoring by central authorities. These retirement homes are seen as a safe shelter for elderly people. ${ }^{46,47}$

The lesson we can learn from the vulnerability analysis matrix is that an evidence-based risk identification method for public health emergency preparedness and response would be appropriate to help risk managers accurately identify uncertainty and hazards. ${ }^{48,49}$ For instance, risk governance applies a targeted method by pinpointing which areas should be considered high risk and which groups are more vulnerable. Such a strategy is adaptive for tackling various situations, rather than relying on a rigid one-size-fits-all method. Figure 2 shows the vulnerability analysis matrix process in the community of Lujiazui.

\section{Empowering Volunteer Groups for Emergency Response}

Academics argue that the social bonds once maintained by work units were destroyed as a result of the economic reform in China. The priority for China's community development is to rebuild and integrate social networks. ${ }^{50}$ Although government organizations remain in charge of community governance, existing literature shows that, in China's developed cities, such as Shenzhen, Guangzhou, Shenyang, and Shanghai, community governance has focused on the pursuit of good governance, highlighting a more efficient and participatory pattern with various stakeholders involved. ${ }^{51-53}$

As previously mentioned, community capacity depends on collaboration, which means that agencies, organizations, neighborhood groups, and public human service systems must work together to plan strategically and, critically, must coordinate their efforts. ${ }^{8}$ Due to the unique system of the Chinese Communist Party (CCP), the party committee at the grassroots level retains the core role of being responsible for risk control and resource allocation in the community. Especially during the COVID-19 outbreak, community authorities obtained more power to control the risks of the disease. However, according to Chinese media, some community authorities were prone to abusing their power, and even to violating the public's rights during the management of the COVID-19 outbreak. ${ }^{54}$ In the community of Lujiazui, the authorities empowered social organizations instead of maintaining centralized power. The community's capacity, enhanced by a collaborative network, significantly improved the effectiveness of the COVID-19 response. An obvious characteristic of the network in the community of Lujiazui is the engagement of volunteer groups. The community authority lacks sufficient human resources for tackling every aspect of community risk governance, and therefore, diverse volunteer groups can act as an auxiliary force.

A volunteer group organized by soldiers and a volunteer group organized by minorities are crucial 


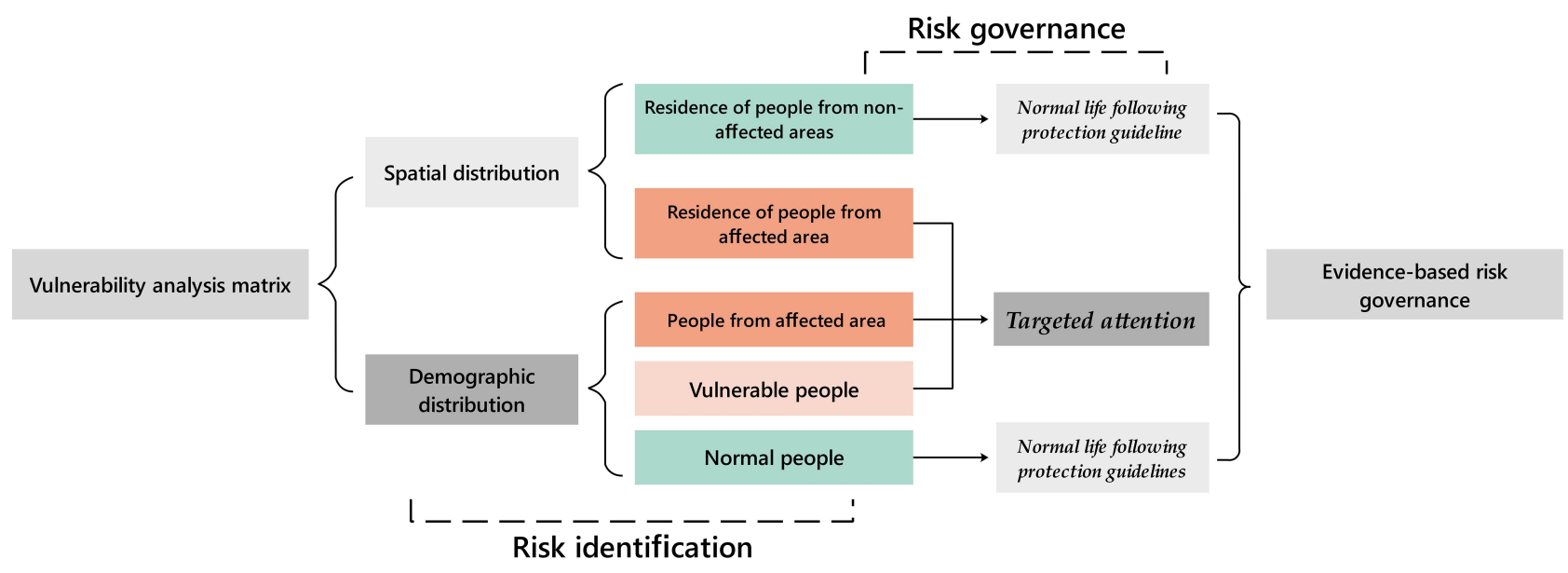

Figure 2 The vulnerability analysis matrix process in the community of Lujiazui.

forces for investigating situations, distributing resources, and supporting logistics. The work style of volunteers represents the emergency ethics of social justice. ${ }^{48}$ Volunteers utilize deliberative methods to show respect toward and communicate with residents to attain their active collaboration instead of relying on enforcement. Soldier volunteers are responsible for helping community workers to investigate health-related situations of residents and the potential risk from covert patients. These soldiers have an understanding of the community in terms of its demographic and geographic conditions. In addition, they can speak the Shanghai dialect, which simplifies communication with Shanghai natives who hardly use Mandarin. Minority volunteers help by informing stores and restaurants to follow the unitary arrangement of outbreak management, and especially to communicate with minority groups in order to respect their customs and habits. Furthermore, some minority volunteers proactively offer preventive equipment, such as masks, to people, as well as food to community workers and other volunteers.

Shanghai is an international metropolis, and a large immigrant population works and lives within it. The community of Lujiazui is the main locality for international residents in Shanghai. Therefore, a distinctive feature in this community is the presence of an immigrant volunteer organization. These volunteers play the role of interpreters, helping community authorities to inform international residents about risk information and reactive policy. The collaboration between Chinese and international residents breaks the communicative barrier in cultural and linguistic divergence and promotes the efficacy of social work for a public health emergency. ${ }^{55}$
Compared to the community of Lujiazui, a community named Zuoling in Wuhan, Hubei province, was more unfortunate when the COVID-19 outbreak occurred. This community is located in a suburb of Wuhan and has the common characteristic of being "not rural but not urban" in China. ${ }^{10}$ In such a governance space, the scarcity of human and material resources impaired the effectiveness of combating the virus. The local authority in charge of strictly confining the community failed to resolve the emergency situation. ${ }^{41}$ This comparative phenomenon shows that resident engagement on the basis of the philosophy of equity, participation, and deliberation in neighborhood life is a cornerstone of successful communities. In the context of a pandemic in a complex environment such as a community, a collaborative network has a significant impact on the performance of managing an outbreak. ${ }^{56,57}$ Figure 3 illustrates the collaborative network in the community of the Lujiazui.

\section{Policy and Action for Public Health Emergency Prevention}

The community of Lujiazui has issued a series of policies and actions for public health emergency prevention in light of previous outbreaks, such as SARS, H1N1, avian influenza, and hand-foot-and-mouth disease. ${ }^{58}$

The strategy of public health emergency prevention in the community of Lujiazui can be approached from two angles: This first is the daily life-oriented method, which aims to enhance public health emergency preparedness, while the second is the organization-oriented method, which is supposed to reinforce the response process. In daily life, the community of Lujiazui endeavors to control 


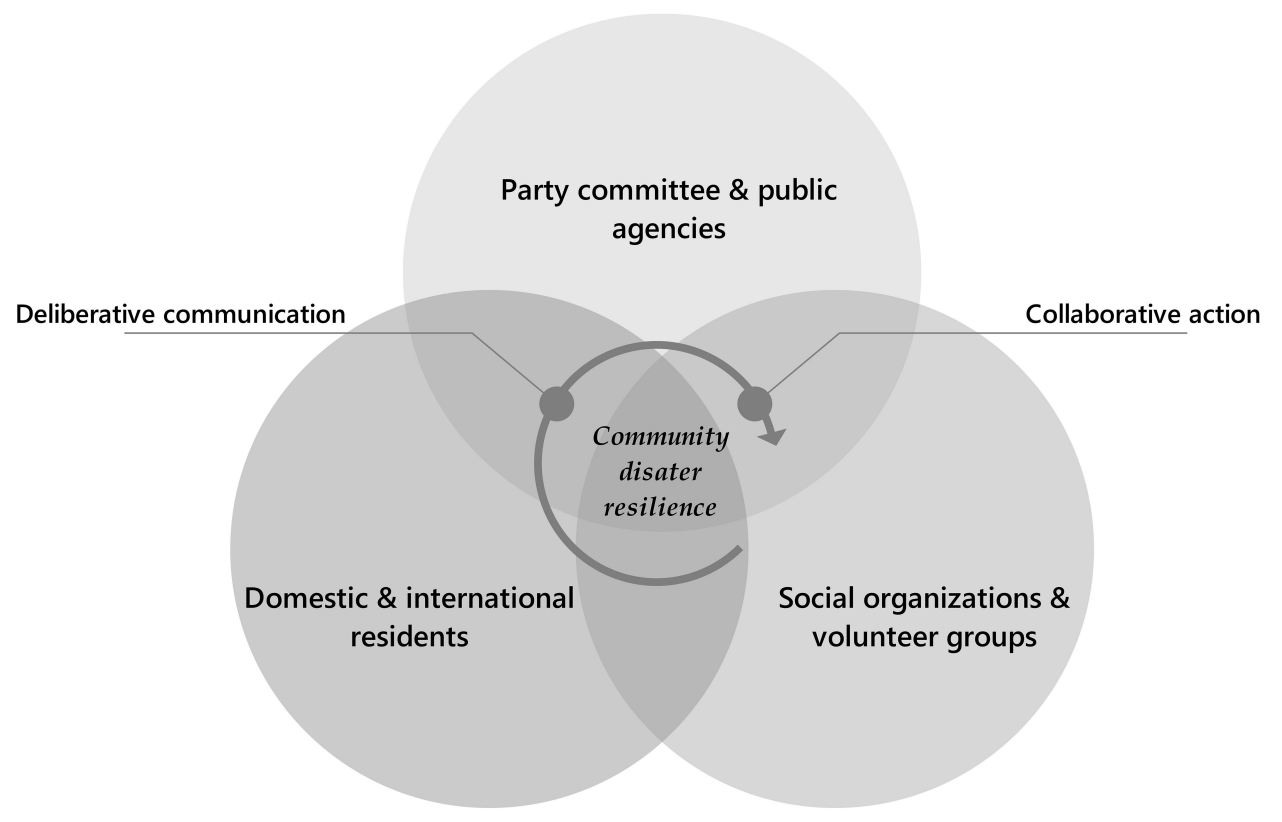

Figure 3 The collaborative network in the community of Lujiazui.

the source of infectious diseases by creating a sanitary and sustainable environment. For instance, the community requires regular maintenance of the public environment, including disinfection of public spaces and pest control. Moreover, the community also focuses on disseminating public health knowledge to the public and assists them in forming an accurate perception of public health risk and scientific healthy behavior. Research indicated that more than $60 \%$ of the emerging infectious disease events that have affected humans over the past several decades have been zoonotic in origin, which means that the diseases are caused by germs that spread between animals and people. ${ }^{59,60}$ Therefore, the strategies of the Lujiazui community for preventing the occurrence of infectious diseases, which involve constructing a sustainable environment and fostering people's health behaviors, match the characteristics of infectious diseases.

In addition to maintaining a sanitary public environment, it is also necessary to strengthen clinical preparedness and response. The international experience of responding to the Ebola outbreak revealed that healthcare resources profoundly influence the effectiveness of public health emergency preparedness and response. For example, health authorities struggled with implementing appropriate mechanisms for diagnosing, transporting, and caring for Ebola patients. ${ }^{61}$ Thus, the community of Lujiazui is dedicated to reserving related protective articles, such as testing equipment, medicines, medical instruments, communicative tools, and transport, with regular renewals and maintenance, so as to ensure the accessibility and availability of healthcare resources.

From the perspective of the organization-oriented method, the community of Lujiazui established a coordinated organization for public health emergency management led by the government. Such an organization enables different groups to prompt response and collaboration, which is the premise of constructing urban governance. Although leadership is separate from governance, leadership is a mechanism for articulating the role of public health agencies in responding to emergencies from different types of hazards, and for ensuring alignment between governance structure and agency plans. ${ }^{62}$ The lead organization has branches for shouldering different responsibilities of general coordination, disinfection, outbreak intervention, information communication, security, market surveillance, and logistical support. Meanwhile, the community also established a health communication system for delivering the outbreak information to vertical and horizontal public health agencies. Figure 4 represents the management plan of the community of Lujiazui for a public health emergency.

\section{Risk Communication for Uncertainty-Oriented Planning}

Risk communication is at the core of the framework of risk governance and is the process of exchanging or sharing 


\section{Core Target: Public health emergency prevention}

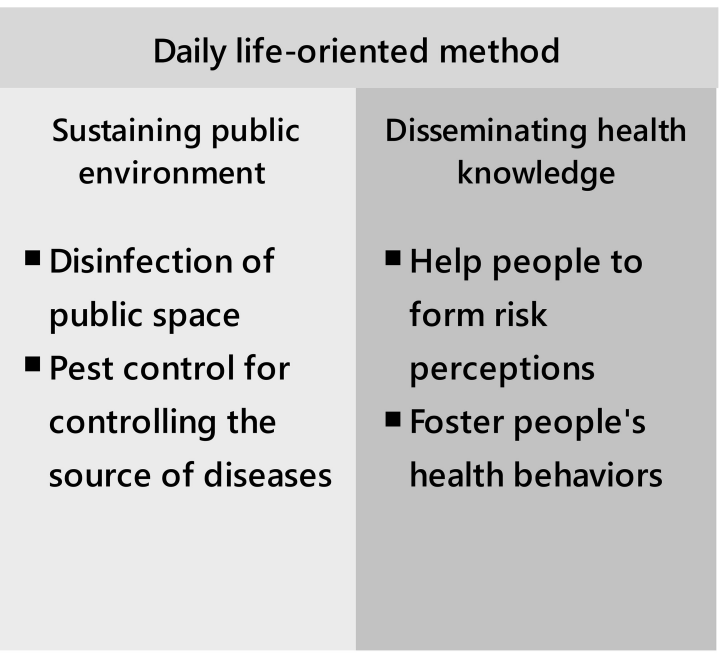

PREPAREDNESS

\section{Effective emergency management}

\section{Organization-oriented method}

The coordinated and lead organization for public health emergency

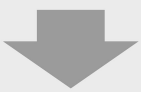

- Branch of general coordination

- Branch of disinfection

- Branch of outbreak intervention

- Branch of information communication

- Branch of security

- Branch of market surveillance

- Branch of logistical support

Figure 4 The management plan of the community of Lujiazui for a public health emergency.

risk-related data, information, and knowledge between and among different groups. ${ }^{63}$ Effective risk communication, to some extent, determines the effectiveness of risk governance. Effective risk communication in a public health context, in general, means that all related risk messages can be shared openly with stakeholders in a timely manner, helping to form accurate risk perceptions and to adjust the public's health behavior to reduce their health risk or to obtain greater benefits in return for the risks that they take. ${ }^{64-66}$ Perception is the basis of action, and inaccurate perceptions stand in the way of concerted action to promote community disaster resilience. ${ }^{33}$ For uncertaintyoriented planning, risk communication assists stakeholders in realizing the potential tend of an outbreak in order to adjust the response method in advance.

The way in which the Chinese local government coped with the outbreak of COVID-19 in Wuhan illustrates ineffective risk communication, including delayed decisionmaking, dishonest information dissemination, and an unscientific communication strategy, which ruined the possibility of a timely response to the outbreak across the country. ${ }^{67}$ However, after Wuhan's lockdown on 23 January 2020, Shanghai's authorities immediately initiated a No.1 level emergency response on 24 January 2020. Following the policies for controlling the virus issued by the central and the Shanghai governments, the community of Lujiazui adopted a principle of information sharing, which aimed to openly convey risk and policy information to the public in a timely manner. Risk communication is important as it enables the public to adopt a preventive strategy and to engage in future risk planning.

As mentioned above, risk communication is an information exchange process between different organizations and agencies. In the community of Lujiazui, a collaborative network frequently constitutes an information network for sharing data and for assessing potential risks. First, different agencies gather information based on their individual perspectives and make a decision following a systematic risk assessment. Second, the community authority integrates decisions issued by various agencies with the aim to avoid conflicts between different policies and to guarantee the uniformity of policy. Lastly, the public can receive all of the risk information and knowledge about the decisions when they are first made.

Risk communication is a highly useful technique. People can only make accurate decisions when they completely understand the content of risk communication, which depends upon how they interpret the communication content and utilize the strategic communicative method. Early risk communication of COVID-19 in Wuhan was ineffective due to the concealment of information, which delayed the control decision and resulted in the virus spreading. ${ }^{66}$ In addition, public health is 
a professional issue where the communicator needs to use clear and evidence-based language to convey information to laypersons. ${ }^{68}$ In Wuhan's outbreak management, the initial risk communication used to explain the epidemiological characteristics of COVID-19 failed to ensure the public understood its risks. The official and expert language was far from evidence-based and was uncertaintyoriented, which resulted in the public adopting the wrong risk perception of the disease. ${ }^{67}$ By contrast, in Shanghai, the authorities were capable of delivering the risk information in a timely manner and explained the quarantine process in simple, plain, and vivid language. For example, a medical expert named Zhang Wenhong from the Shanghai official public health system said, from now, it is important to know that everyone is a fighter. We can defeat the virus so long as you stay at home for 2 weeks. You are not in quarantine, you are fighting! You feel like you are suffocating, but you can suffocate the virus! What you can rely on is yourself instead of a doctor. ${ }^{69}$ Furthermore, Zhang Wenhong edited a popular handbook on the prevention and control of COVID-19 in daily life. This book has become a crucial guide for the health behavior of the public and will be translated into 13 languages. ${ }^{70}$ Following this principle, the community of Lujiazui conveys the knowledge of preventive practices based on COVID-19 research and uses social media to make risk communication easy to understand. Figure 5 is a simplified model of the risk communication of the community of Lujiazui during the COVID-19 outbreak.

To sum up, effective risk communication enhances the trust and confidence of the public in risk governance institutions. $^{2}$ Through effective communication, stakeholders will understand what they should and should not do, which establishes the premise for a collaborative network and community disaster resilience.

\section{Discussion and Conclusions}

The practice of the community of Lujiazui illustrates how community disaster resilience copes with the COVID-19 outbreak. This article analyzed the case of the community of Lujiazui using the conceptual framework of resilient cities. Based on the principles we summarized, here we mention some recommendations to other communities in different countries for improving community disaster resilience:

1. Accurate and targeted identification of vulnerability and potential risk. For example, the community can use the information technology to identify existent and potential risk spot. Adopting the flexible management on the risk spot instead of a one-size-fit s-all strategy, which aims to ensure the liberty of health people.

2. Empowering social organizations in communities. Establishing a public-private collaborative network by engaging all related stakeholders, which make all actors combat the virus proactively rather than conforming to the rigid measures passively.

3. Resource preparedness for preventing risks. Every community ought to conduct full preparations for a public health emergency, including medical supplies, community medical institutions, and necessary

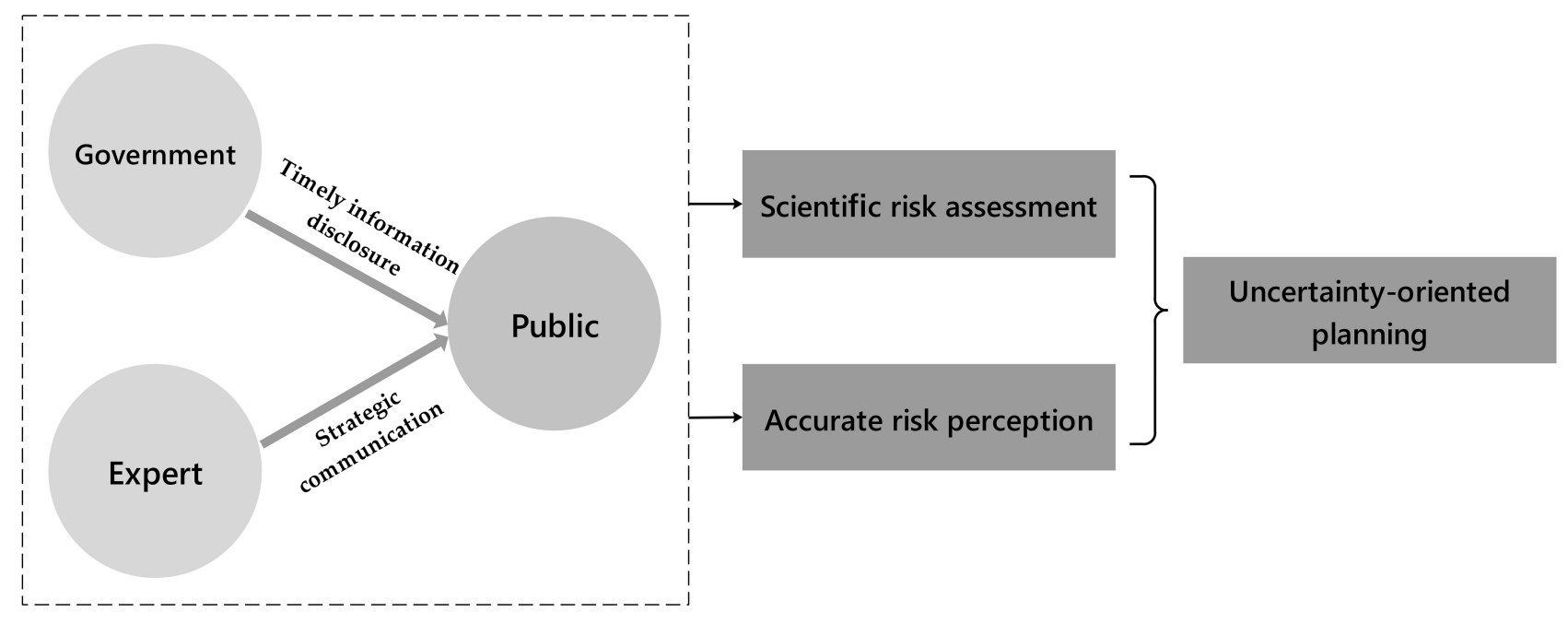

Figure 5 A simplified model of the risk communication of the community of Lujiazui. 
medical equipment. In addition, the community also should sustain a sanitary environment.

4. Timely information disclosure and effective risk communication. In daily life, the community should disseminate related knowledge to improve people's health literacy. In the pandemic, the community should deliver risk information timely and honestly, which enables the public to conduct scientific health behavior and to participate in the outbreak management proactively.

In summary, such an integrated approach indicates that the key to successful outbreak management at the community level is to build an interactional order, integrating autonomy, resilience, and authority. Based on this premise, risk communication can be used to avoid the Tacitus Trap by making risk governance credible and effective, while a collaborative network will stimulate the capacity of stakeholders to provide public services, and the vulnerability analysis shows its evidence-based advantage when used to conduct targeted risk prevention. In other words, only by incorporating complementary capacities and veritable interaction amongst stakeholders into community governance can community disaster resilience work.

In essence, community disaster resilience represents a flexible and prompt governance network. At the core of effective community disaster resilience is how to establish a network in a timely manner during a risk event. Even though China's response to the COVID-19 outbreak demonstrated harsh community lockdown, which has an advantage in terms of restricting the transmission of the virus, such a lockdown is a passive strategy of risk governance. Building resilience is neither a quick fix nor a process that can be achieved through top-down pressure alone. Therefore, effective risk governance relies on sharing responsibility by all agencies and all people involved. Perceived risk can motivate individuals; people are more willing to change their behavior if they have the feeling of "being at war", and the way in which an individual perceives risk depends on effective communication. ${ }^{9,12,71}$ In addition, risk management is a multidisciplinary issue that integrates science and technology. Especially for environmental hazards and public health risk, accessible and practicable technology is a premise of effective risk governance. For instance, in the absence of a curative method or vaccines, the best countermeasure for preventing virus transmission is to maintain social distance and to wear preventive equipment. In brief, community disaster resilience can be seen as a function comprising the different variables of network cooperativity, availability of technology, and effectiveness of communication.

The construction of community disaster resilience is not only related to the internal structure of a community but also depends on the external environment in which the community is embedded. ${ }^{72}$ In this sense, we cannot ignore the fact that the success of the community of Lujiazui, to an extent, depended upon the unique characteristics of the community formed under Shanghai's special economic, political, and international conditions. Whether Lujiazui's experience can be promoted and copied needs to be verified in practice. Such a correlation between the external environment and community resilience needs to be empirically studied based on a large sample in the future. However, as mentioned, resilient communities share similarities. If it is difficult to control the external environment, a community can change its internal structure and relationships, and can construct an institutionalized mechanism of public-private collaboration. Collaboration between the private and public sectors could improve the ability of a community to mitigate, prepare for, respond to, and recover from natural or human-caused disasters. ${ }^{33}$ Based on this, our study is not without limits. The future research should focus on the comparative study between a resilient community and a non-resilient community, which can further clarify how the community disaster resilience improves the capacity to cope with the public health emergency.

The COVID-19 outbreak highlights that humans still face various unpredictable risks in the future. However, these risks also create opportunities for society. Under the potential threat of risks, people can engage in cohesion and collaboration, thus forming a connection-based resilience that fosters the sharing of responsibilities, values, and goals. Whether at the community, national, or global level, resilience will make us more rational and hardheaded, and will also make our lives and our environments more sustainable.

\section{Ethics Statement}

Exemption of Ethical Approval: The interview materials are related to public administration instead of medical research. The public administration interviews are not considered research that requires ethical approval, and that informed consent was obtained from all concerned. All liabilities associated with the utilization of interview materials are borne by the authors. 


\section{Acknowledgment}

We would like to thank the interviewees in the Lujiazui community.

\section{Disclosure}

The authors report no conflicts of interest in this work.

\section{References}

1. Beck U. Risk Society: Towards a New Modernity. New York: SAGE Publications; 1992.

2. Renn O. Risk Governance: Coping with Uncertainty in a Complex World. London: Earthscan; 2008.

3. Beck U. Power in the Global Age. Malden: Polity Press; 2005.

4. Shiroyama H, Yarime M, Matsuo M, et al. Governance for sustainability: knowledge integration and multi-actor dimensions in risk management. Sustain Sci. 2012;7:45-55. doi:10.1007/s11625-0110155-Z

5. Jabareen Y. The Risk City. New York: Springer; 2015.

6. Comfort LK. Building community resilience to hazards. Safety Sci. 2016;90:1-4. doi:10.1016/j.ssci.2015.09.031

7. Komino T. Community resilience: why it matters and what we can do. Ecumenical Rev. 2014;66:324-329. doi:10.1111/erev.12109

8. Virginia G, Kilmer RP. Building community capacity and fostering disaster resilience. J Clin Psychol. 2016;72:1318-1332. doi:10.1002/ jclp.22281

9. Fitzpatrick T. Community disaster resilience. In: Clements BW, Casani J, editors. Disasters and Public Health: Planning and Response. Burlington: Elsevier; 2016.

10. Zhong R, Mozur P To tame coronavirus, mao-style social control blankets China. Available from: https://www.nytimes.com/2020/02/ 15/business/china-coronavirus-lockdown.html?_ga $=2.205023314$. 358041378.1586185090-628437207.1586185090. Accessed May 5, 2020.

11. Violent law enforcement is also a virus. Available from: http://pinglun. eastday.com/p/20200306/u1ai20396960.html. Accessed December 3, 2020

12. Chongqing found 14 infectious cases in communities. Available from: http://www.cq.xinhuanet.com/2020-02/04/c_1125528118.htm. Accessed December 3, 2020.

13. Cork S. Resilience and Transformation: Preparing Australia for Uncertain Futures. Melbourne: CSIRO Publishing; 2010.

14. Pasman H, Kirillov IA. Resilience of Cities of Terrorist and Other Threats. Dordrecht: Springer; 2007.

15. Gunderson L, Holling CS. Panarchy: Understanding Transformations in Human and Natural Systems. Washington: Island Press; 2001.

16. Paton D, Johnston DM. Disaster Resilience. Springfield: Charles C. Thomas; 2006.

17. Maguire B, Hagan P. Disasters and communities: understanding social resilience. Aust J Emerg Manag. 2007;22:16-20.

18. Masterson JH, Peacock WG, Van Zandt SS, et al. Planning for Community Resilience: A Handbook for Reducing Vulnerability to Disasters. London: Island Press; 2014.

19. Cox RS, Hamlen M. Community disaster resilience and the rural resilience index. Am Behav Sci. 2015;59:220-237. doi:10.1177/ 0002764214550297

20. Arbon P. Developing a model and tool to measure community disaster resilience. Aust J Emerg Manag. 2014;29:12-16.

21. Morris JC, Mcnamara MW, Belcher A. Building resilience through collaboration between grassroots citizen groups and governments: two case studies. Public Works Manag P. 2019;24:50-62. doi:10. $1177 / 1087724 X 18803116$
22. Cutter SL, Barnes L, Berry M, et al. Community and regional resilience: perspectives from hazards, disasters, and emergency management. Geography. 2008;1:2301-2306. doi:10.1073/pnas.071 0375105

23. Amaratunga CA. Building community disaster resilience through a virtual community of practice (VCOP). Int $J$ Disaster Resil. 2014;5:66-78. doi:10.1108/IJDRBE-05-2012-0012

24. McCarthy DM, Chiampas GT, Malik S, et al. Enhancing community disaster resilience through mass sporting events. Disaster Med Public. 2011;5:310-315. doi:10.1001/dmp.2011.46

25. Coetzee C, Van Niekerk D, Raju E. Disaster resilience and complex adaptive systems theory. Disaster Prev Manag. 2016;25:196-211. doi:10.1108/DPM-07-2015-0153

26. Harrison CG, Williams PR. A systems approach to natural disaster resilience. Simulation Modelling Practice Theory. 2016;65:11-31. doi:10.1016/j.simpat.2016.02.008

27. Coaffee J, Wood MD, Rogers P. The Everyday Resilience of the City: How Cities Respond to Terrorism and Disaster. New York: Palgrave Macmillan; 2008.

28. Matarrita-Cascante D, Trejos B, Qin H, et al. Conceptualizing community resilience: revisiting conceptual distinctions. Community Dev. 2017;48:105-123. doi:10.1080/15575330.2016.1248458

29. National Research Council. Building Community Disaster Resilience Through Private-Public Collaboration. Washington DC: The National Academies Press; 2011.

30. RAND Corporation. Building community resilience to disasters: a way forward to enhance national health security. Available from: https://www.rand.org/content/dam/rand/pubs/technical_reports/2011/ RAND_TR915.pdf. Accessed May 5, 2020.

31. Becker J, Johnston D, Lazrus H, Crawford G, Nelson D. Use of traditional knowledge in emergency management for tsunami hazard: a case study from washington state. Disaster Prev Manag. 2008;17:488-502. doi:10.1108/09653560810901737

32. Crow DA, Albright EA, Ely T, Koebele E, Lawhon L. Do disasters lead to learning? Financial policy change in local government. Rev Policy Res. 2018;35:564-589. doi:10.1111/ropr.12297

33. Beer T, Ismail-Zadeh A. Risk Science and Sustainability Science for Reduction of Risk and Sustainable Development of Society. Dordrecht: Springer Science+Business Media; 2003.

34. Winnard J, Adcroft A, Lee J, et al. Surviving or flourishing? Integrating business resilience and sustainability. J Strategy Manag. 2014;7:303-315. doi:10.1108/jsma-11-2012-0059

35. Becker P. Sustainability Science: Managing Risk and Resilience for Sustainable Development. Waltham: Elsevier; 2014.

36. Magis K. Community resilience: an indicator of social sustainability. Soc Natur Resour. 2010;23:401-416. doi:10.1080/08941920903305674

37. Tobin GA. Sustainability and community resilience: the holy grail of hazards planning? Envir Hazard. 1999;1:13-25. doi:10.3763/ ehaz.1999.0103

38. Pirlone F, Spadaro I, Candia S. More resilient cities to face higher risks. The Case of Genoa. Sustainability. 2020;12:4825. doi:10.3390/ su12124825

39. Jennings B, Arras JD, Barrett DH, et al. Emergency Ethics: Public Health Preparedness and Response. New York: Oxford University Press; 2016.

40. Sherrieb K, Norris FH, Galea S. Measuring capacities for community resilience. Soc Indie Res. 2010;99:227-247. doi:10.1007/s11205-0109576-9

41. Qin A, Wee S. In China's war on the coronavirus, a community is besieged. Available from: https://www.nytimes.com/2020/02/28/ world/asia/china-coronavirus-wuhan.html?_ga=2.39751840. 267427338.1586435198-628437207.1586185090. Accessed May 5, 2020.

42. Investigation on the population carrying capacity in Pudong District, Shanghai (II). Available from: https://www.thepaper.cn/newsDetail_ forward_1253669. Accessed December 3, 2020. 
43. Wolf S. Vulnerability and risk: comparing assessment approaches. Nat Hazards. 2012;61:1099-1113. doi:10.1007/s11069-011-9968-4

44. Stephenson N, Davis M, Flowers P, et al. Mobilising 'vulnerability' in the public health response to pandemic influenza. Soc Sci Med. 2014;102:10-17. doi:10.1016/j.socscimed.2013.11.031

45. World Health Organization. Coronavirus disease (COVID-19) advice for the public. Available from: https://www.who.int/emergencies/dis eases/novel-coronavirus-2019/advice-for-public. Accessed May 5, 2020.

46. Peinado F, Viejo M Coronavirus crisis in Madrid's senior homes: if he gets infected, no one will do anything to help him. Available from: https://english.elpais.com/society/2020-03-20/coronavirus-crisis-inmadrids-senior-homes-if-he-gets-infected-no-one-will-do-anything-to -help-him.html. Accessed May 5, 2020.

47. Sohu News. In the COVID-19 outbreak, do old people live well at senior homes in Shanghai? Available from: https://www.sohu.com/a/ 380842149_120096342. Accessed May 10, 2020.

48. Brownson RC, Baker EA, Leet TL, et al. Evidence-Based Public Health. (Second. New York: Oxford University Press; 2011.

49. Mahapatra $P$. The need for evidence-based public health response in disasters. J Evid Based Med. 2014;7:238-244. doi:10.1111/jebm. 12129

50. Wu X, Yan H, Jiang Y. How are new community governance structures formed in Urban China? Asian Surv. 2018;58:942-965. doi:10.1525/as.2018.58.5.942

51. Bray D. Building "community": new strategies of governance in Urban China. Econ Soc. 2006;35:530-549. doi:10.1080/03085140 600960799

52. Ma W, Li LC. Community governance reform in urban china: a case study of the yantian model in Shenzhen. J Comp Asian Dev. 2012;11:224-247. doi:10.1080/15339114.2012.720127

53. Lin WI, Kuo C. Community governance and pastorship in shanghai: a case study of Luwan District. Urban Stud. 2013;50:1260-1276. doi:10.1177/0042098012465903

54. China Daily. Excessive and Violent Enforcement is strictly prohibited. Available from: http://cnews.chinadaily.com.cn/a/ 202002/19/WS5e4cb9d8a3107bb6b57a0b63.html. Accessed May $12,2020$.

55. Shanghai Volunteer. Foreigner Volunteers in Shanghai Community: do not call me "Foreigner", I am a Shanghai Resident. Available from: http://www.volunteer.sh.cn/website/News/NewsItem.aspx?id= 13515. Accessed May 12, 2020.

56. Sapna S, Morenoff JD. Building community: the neighborhood context of social organization. Soc Forces. 2006;3:3. doi:10.1353/ sof.2006.0058

57. Hossain L, Bdeir F, Crawford JW. Networks of preparedness and response during Australian H1N1 outbreak. Disaster Med Public. 2015;9:155-165. doi:10.1017/dmp.2014.88
58. Emergency plan for important public health outbreak of Lujiazui Street. Available from: https://max.book118.com/html/2017/0903/ 131655925.shtm. Accessed May 24, 2020.

59. Jones KE, Patel NG, Levy MA, et al. Global trends in emerging infectious diseases. Nature. 2008;451:990-993. doi:10.1038/nature 06536

60. Center for Disease Control and Prevention. Zoonotic Diseases. Available from: https://www.cdc.gov/onehealth/basics/zoonoticdiseases.html. Accessed December 3, 2020.

61. Jacobsen KH, Aguirre AA, Bailey CL, et al. Lessons from the Ebola outbreak: action items for emerging infectious disease preparedness and response. Eco Health. 2016;13:200-212. doi:10.1007/s10393016-1100-5

62. Khan Y, O'Sullivan T, Brown A, et al. Public health emergency preparedness: a framework to promote resilience. BMC Public Health. 2018;18:1344. doi:10.1186/s12889-018-6250-7

63. IRGC. Introduction to the IRGC Risk Governance Framework, Revised Version. Lausanne: International Risk Governance Center; 2017.

64. Fischhoff B, Bostrom A, Quadrel MJ. Risk perception and communication. Ann Rev Publ Health. 1993;14:183-203. doi:10.11 46/annurev.pu.14.050193.001151

65. Frewer L. The public and effective risk communication. Toxicol Lett. 2004;149:391-397. doi:10.1016/j.toxlet.2003.12.049

66. Árvai J, Rivers LIII. Effective Risk Communication. London: Routledge; 2014.

67. Zhang L, Li H, Chen K. Effective risk communication for public health emergency: reflection on the COVID-19 (2019-nCoV) Outbreak in Wuhan, China. Healthcare. 2020;8:64. doi:10.3390/ healthcare 8010064

68. Sellnow T, Ulmer RR, Seeger MW, et al. Effective Risk Communication: A Message-Centered Approach. New York: Springer; 2009.

69. NetEase News. The leader of shanghai experts group: everyone is fighter, suffocating the virus for two weeks. Available from: https:// news.163.com/20/0207/05/F4OSC8P50001899O.html. Accessed May 21, 2020.

70. Tencent News. Zhang wenhong's handbook has 13 sorts of languages version: shanghai's experience for outbreak management is going to the world. Available from: https://new.qq.com/omn/20200403/ 20200403A0OUR000. Accessed May 21, 2020.

71. Wilderer PA, Renn O, Grambow M, et al. Sustainable Risk Management. Gewerbestrasse: Springer International Publishing; 2018.

72. Carmit R, Tzipi HL, Odeya C, et al. The relationship between community type and community resilience. Int $J$ Disast Risk Re. 2018;31:470-477.
Risk Management and Healthcare Policy

\section{Publish your work in this journal}

Risk Management and Healthcare Policy is an international, peerreviewed, open access journal focusing on all aspects of public health, policy, and preventative measures to promote good health and improve morbidity and mortality in the population. The journal welcomes submitted papers covering original research, basic science, clinical \& epidemiological studies, reviews and evaluations, guidelines, expert opinion and commentary, case reports and extended reports. The manuscript management system is completely online and includes a very quick and fair peer-review system, which is all easy to use. Visit http://www.dovepress.com/testimonials.php to read real quotes from published authors. 